\title{
Culturally Situated Critical Mathematics Education
}

\author{
Annica Andersson and David Wagner
}

\begin{abstract}
Based on a synthesis of connections between ethnomathematics and critical mathematics education, we present a set of four "concerns," framing what we call culturally situated critical mathematics education. We see any ethnomathematics or critical mathematics education work as fitting within this framing. We illustrate the framework with an analysis of two empirical articles, one reporting an ethnomathematical teaching and research project in a Sámi context, and one reporting on a critical mathematics education teaching and research project in an underprivileged context in the USA. Our analysis shows how the concerns bring the strengths of ethnomathematics to critical mathematics education and vice versa.
\end{abstract}

\section{Keywords}

critical mathematics education - ethnomathematics - cultural situatedness

For several years, we have engaged in conversations about ethnomathematics and critical mathematics education. These are labels that may be identified as theoretical research areas, research methodologies and/or pedagogies. We have asked ourselves questions about the relationship between ethnomathematics and critical mathematics education and about how these differences are connected to theory and practice. We have also asked ourselves in what geographical spaces each of these approaches is used. Who in our field applies ethnomathematical theories or critical mathematics education theories in their research work and who critiques it?

In this chapter, we explore the possibility of synthesising critical mathematics education and ethnomathematics. Through our previous work, which we see as located within both fields, we see each approach informing the other. Through a discussion of ethnomathematics and critical mathematics education, we tease out and discuss the intersections between them. We address

(C) ANNICA ANDERSSON AND DAVID WAGNER, 2021 | DOI: 10.1163/9789004465800_002

This is an open access chapter distributed under the terms of the CC BY 4.0 License. 
the question about differences by first focusing on commonalities, and come to see that the differences may be seen as variations of similar orientations. In this vein, we propose a synthesised culturally situated critical mathematics education as a framework, structured around a set of guiding analytical "concerns." This framework encompasses both ethnomathematics and critical mathematics education in a way that brings the strengths of each to the other. We apply this framework to analyse two empirical articles: one by Nutti (2013), who accounts for ethnomathematical research and teaching in Indigenous Sápmi context; and one by Rubel et al. (2016) who give an account of critical mathematics education in a disadvantaged North American context. With this analysis, we demonstrate how the framework can help researchers using critical mathematics education and/or ethnomathematics reflect on their work.

\section{1 \\ Locating Ethnomathematics}

We begin with an overview of our prior work in which we mapped the trajectory of ethnomathematics and asked what could be counted as ethnomathematical research within the Mathematics Education and Society (MES) conference proceedings (Andersson \& Wagner, 2015). For this analysis, we searched for ethnomathematics (and other forms of the word by searching on ethnomathematic*) in all accepted symposia and papers in the proceedings. We found some interesting numbers to unpack further. For example, for a high number of the papers in which we found the word ethnomathematics, the word was only used once or twice; these papers were not focusing on ethnomathematical research in particular. In an even higher number of papers, the word or a form of it was present only in the reference list. In contrast to the word ethnomathematics, the word culture (or its variant, cultural) was present in almost all accepted MEs papers. The word culture was used in a variety of contexts, usually in a nominal way, with no theorisation of culture or the place of culture in mathematics. The word anthropology was rare.

As an example of potential ethnomathematical work, we decided that it could make sense to place any work on language register as ethnomathematical because it focuses on an artefact (mathematics language) of a specific culture (a language register). For example, Zolkower and de Freitas (2010) "guided [teachers in the] deconstruction of whole-group interaction texts selected as paradigmatic instantiations of this genre" (p. 509). Their attention to a genre, which is a part of the mathematics classroom register, would seem to place the work in a culture, but their reporting does not connect the language practice to the culture. Their investigation of linguistic patterns is not uncommon in 
the field, including some of our own work (e.g., Herbel-Eisenmann \& Wagner, 2010). We find that such work is not identified as ethnomathematical, though we see that it could be designated as such.

Our closer look at the MES papers in which ethnomathematics appeared more than once in the body of the text found that the largest number of these papers used ethnomathematical research to justify and/or position their own research, and/or, in a few sentences, show awareness that ethnomathematics exists. Fewer papers specifically situated the research in ethnomathematical theories. There were also papers that talked about ethnomathematical research: such papers may argue that ethnomathematical research is important, should be done with care and awareness, or raise concerns-for example concerns about exoticism or, as in the papers from South Africa, about ghettoisation.

Almost all papers in the MES proceedings raise concerns about cultural aspects and/or particular cultural groups. However, the number of papers explicitly addressing, critiquing, or discussing ethnomathematical research is low. This finding highlights the significance of culture to sociocultural and sociopolitical research even when it is not explicitly ethnomathematical. We also found interesting the demographics of who does ethnomathematics and who critiques it. In general, we found that explicitly ethnomathematical work has been done in colonised settings, and critiques of ethnomathematics have been done by people of coloniser cultures, with the exception of researchers from South Africa, whose experiences with Apartheid motivated concerns about the ghettoisation of groups of people.

\section{Locating the Myth of Culture-Free Mathematics}

Critiques of ethnomathematics and the relative paucity of explicitly ethnomathematical work (even at MES conferences) point to a general avoidance of ethnomathematics in our field. We also have anecdotal evidence of a general rejection of ethnomathematics; each of us has written about our early interest in ethnomathematics and the lack of encouragement we received in the field (Andersson \& Wagner, 2015). We think that the myth that mathematics is free of culture is part of the reason for this rejection. But this does not explain the rejection of ethnomathematics from scholars who acknowledge the cultural nature of mathematics. Hence, we consider it necessary to elaborate the basic myth of a non-cultural mathematics, which we consider to be the most significant myth related to mathematics, most certainly to ethnomathematics but maybe also in relation to critical mathematics education.

The word myth is used generally to describe something that is not true. However, we see myths as the stories people use to interpret their experience- and 
they can go beyond stories, to include any texts (words, images, memes, etc.). These stories are common expressions of widespread belief. In this way, myth may also be regarded as formative. What makes something a myth is not its falseness but rather its pervasiveness in a discourse and/or a culture. We have elaborated this view of myth elsewhere (Andersson \& Wagner, 2018; Wagner, 2019), a view that follows Barthes (1957/2009) and connects with anthropological perspectives on myth (e.g., Geertz, 1974).

The view that mathematics is free of culture is a myth because it is a widespread belief. The view is also mythic because it is a view that is generally unfounded, which is not to say that it is (completely) untrue-it is what Barthes (1972/2009) calls a tautology, one of the rhetorical tools of myth he identified. The myth about mathematics being free of culture is not completely untrue because mathematics characteristically aims for abstraction and generalisation. In other words, it generally steps away from particularities, context, and thus culture. However, we see such moves for abstraction as human moves, and they are thus situated. The move for abstraction is a move within culture, so we do not see abstraction as culture-free. Jurdak's (2016) conclusions in his article about ethnomathematics and real-world problem solving in schools resonate with our view:

The contribution of ethnomathematics to mathematics education is vital as far as its illumination of the cultural value of linking mathematics to culture and of the educational value of ethnomathematical practices in the learning and teaching of mathematics. (p. 131)

Related to the myth of culture-free mathematics, scholarship has a range of perspectives of how to think of academic mathematics as a culture. We identify three different scholarly positions on the relationship between ethnomathematics and academic mathematics. We notice that they each verify the significance of the myth that math is culture-free.

In 1996, in his early work on defining ethnomathematics as a research program (building on the work by Ubiritan D'Ambrosio, Marcia Ascher and Paulus Gerdes), Barton (1996) stated that:

Ethnomathematics is a research programme of the way in which cultural groups understand, articulate and use the concepts and practices which we describe as mathematical, whether or not the cultural group has a concept of mathematics. (p. 214)

In other words, the 'we' indicates that what 'we' (as academic mathematicians, outside of culture) define as mathematics is the norm to which 
ethnomathematics is to be explored and explained. At the same point in time, Borba (1997) viewed ethnomathematics as an (kind of) academic mathematics and argued that:

The accepted mathematics ... ranges from ones developed by students to the one accepted/developed/intended by the teacher. In the classroom dialogue, the teacher can learn from the ethnomathematics "spoken" by the students, just as the students are learning from the academic ethnomathematics of the teacher. (p. 268)

However, this quotation still positions academic mathematics as the norm - as the mathematics stated in school jurisdiction steering/curriculum documents and hence to be distributed by the teacher. Academic mathematics is the mathematics that is acceptable to teach and to explore. This alienates students who come to class with other mathematics-ethnomathematics.

Some years later, Rowlands and Carson (2002) firmly asserted in a critical, and critiqued, article about ethnomathematics that:

The goal of ethnomathematics should be to examine human mathematical thinking in tribal cultures in order to help students recognise both the universal nature of human ingenuity and the remarkable diversity of its many forms of expression. As an introduction to the historical origins of mathematical thought worldwide, it is a potentially useful practice. However, to substitute a curriculum of ethnomathematics for instruction in formalised, modern mathematics may become a form of cultural disenfranchisement. (p. 92)

They concluded by stating that:

Mathematics is universal because, although aspects of culture do influence mathematics, nevertheless, these cultural aspects do not determine the truth content of mathematics: Pythagoras' theorem was developed by the Greeks and independently by the Chinese a century and a half later and 'Pascal's triangle' was developed by the Chinese centuries before Pascal. Mathematics transcends the civilisations of ancient Greece and China and the France of Pascal and it is this universalism that has to be emphasised in the classroom-rather than the geometrical patterns in traditional crafts. (p. 98)

Hence, there is a tension in our field about how to position ethnomathematics and academic (western) mathematics in relation to each other, both in research 
and in school mathematics. Most mathematics education scholars position academic mathematics as the norm, and as we have shown above, even ethnomathematicians often position academic mathematics as the norm. Others see academic mathematics and ethnomathematics either as complementary or as informing each other.

Parra (2018) has confronted the tension between these positionings by seeing mathematics as performative. Mathematics is done in different cultures. If someone from one culture encounters mathematics being done in another culture, it is necessary for them to interpret that mathematics through their own cultural lens. Parra encouraged a focus on the interactions between the people in a culture and the ethnomathematician. Parra's approach sidesteps the myth of culture-free mathematics (probably intentionally).

We consider the myth of a culture-free mathematics through the different tensions that we identify in relation to ethnomathematics with the purpose of considering possible reasons for avoiding ethnomathematics. First, a tension between structuralism and functionalism are central to the myth of culture-free mathematics. Structuralism takes commonalities as evidence of a human essence on which language is structured. Functionalism takes these commonalities as evidence that people in different cultures are responding to similar challenges and thus invent similar ways of responding to these challenges. Applying this idea to ethnomathematics, we can distinguish between people who see a mathematical essence (mathematical truth) that manifests in different cultures and people who see mathematics as situated (as human responses to particular situations). We think that most ethnomathematics researchers have the functionalist perspective: mathematics arises out of particular contexts (and these contexts may have similarities resulting in some similar mathematics), but Rowlands and Carson (2002) take a structuralist perspective.

The "truth" in the myth described above relates to the characteristic move to or for abstraction in mathematics. From a functionalist perspective, humans in many cultures have found it helpful to make such moves for abstraction - to look for patterns and commonalities across particular contexts and to try to think about these things separate from the contexts. From a structuralist perspective, abstraction would be seen as a set of pre-existing truths that humans can work at uncovering, and different cultural mathematics are therefore seen as multiple perspectives on the same thing. We see elements of both approaches within ethnomathematics scholarship. For example, Borba (1997) could be seen to value understanding different perspectives as a way of getting a better picture of the truth (that is structuralism) or to value mathematics as a medium through which to understand better the contexts of different people (that is functionalism).

Second, ethnomathematics may be seen as a form of colonialism. There might be a view that ethnomathematics is just another instance of taking 
riches from other cultures. Colonialists first took (and continue to take) the resources from other people's land and from the land itself. This extraction is a form of abstraction. We sell them a 'better life' (our culture, our languages), leaving behind only remnants of their culture and language. And now, with ethnomathematics we aim to take their ideas (their mathematics) and maybe make them ours. This could be a structuralist perspective in which we see ethnomathematics as mining for new perspectives so that we can understand better the things we are all trying to understand. If we accept this structuralist view, then we might feel that it is warranted to dig together with diverse people to find the treasure and share it, but to do this with cultural sensitivity.

Third, we reflect on what Dowling (1998) called the "myth of emancipation." In response to the work of Paulus Gerdes, Dowling noted that the "difficulty is that it appears that a European is needed to reveal to the African students the value inherent in their own culture" (p.12) and that this revelation is done in European terms. This criticism is problematic because Gerdes became a citizen of Mozambique and renounced his Dutch citizenship. We do not see abstraction from culture as particularly relevant to Dowling's challenge of ethnomathematics. Nevertheless, Dowling's criticism addresses a motive that is commonly expressed by people who do ethnomathematics - for example, Gerdes (1997) wrote that ethnomathematics has emancipatory power because uncovered mathematical practices can inspire confidence in students who may assume that they cannot do mathematics. We would argue along the lines of Borba (1997) and Parra (2018) that the judging can go both ways - academic mathematics may be used to evaluate (consider the benefits of) another culture's mathematics and vice-versa.

Fourth, a wariness of colonialism and ethnomathematics may be an expression of fear of addressing thorny issues. This fear may be stronger amongst people of privilege, perhaps because we are less motivated to change the structures that have brought us privilege. Our counting of MES papers showed the tendency for ethnomathematics to be taken up in colonised settings, although we could not determine the motive for the tendency.

In the previous section, we examined the cultural situatedness of ethnomathematics by considering the locations from which it is done and critiqued. In this section, we do something similar with critical mathematics education, which is the focus of this book. Critical mathematics education has developed in two geographically different contexts: a Scandinavian tradition and a North American tradition. 
The Scandinavian tradition started in Norway with Stieg Mellin-Olsen's (1987) sociopolitical work, and was followed in Denmark by the rich production of Ole Skovsmose (e.g., 1994, 2001) and others. In this tradition, Skovsmose formulated critical mathematics education as addressing a range of "concerns" which Skovsmose and Nielsen (1996) articulated as follows:

a. Citizenship identifies schooling as including the preparation of students to be an active part of political life.

b. Mathematics may serve as a tool for identifying and analysing critical features of society, which may be global as well as having to do with the local environment of students.

c. The students' interest emphasises that the main focus of education cannot be the transformation of (pure) knowledge; instead educational practice must be understood in terms of acting persons.

d. Culture and conflicts raise basic questions about discrimination. Does mathematics education reproduce inequalities which might be established by factors outside education but, nevertheless, are reinforced by educational practice?

e. Mathematics itself might be problematic because of the function of mathematics as part of modern technology, which no longer can be reviewed with optimism. Mathematics is not only a tool for critique but also an object of critique.

f. Critical mathematics education concentrates on life in the classroom to the extent that the communication between teacher and students can reflect power relations. (p. 1257)

The first of these concerns covers the whole of critical mathematics education, constructing a concept of citizenship that assumes an active political life. We emphasise that political activity requires engagement with local contexts, which include both environmental and cultural considerations. In other words, political activity is by nature situated. This situated aspect of critical mathematics education connects with traditional definitions of ethnomathematics, such as Barton's (1996) characterisation of it as being interested in how "cultural groups understand, articulate and use the concepts and practices which we describe as mathematical" (p. 214). A significant difference is that critical mathematics education engages students in doing mathematics in a cultural situation, while traditional ethnomathematics studies, observes and documents the mathematics done in a cultural situation.

In addition to the Scandinavian branch of critical mathematics education, we recognise the branch of critical mathematics education developed by 
North American researchers such as Gutstein (e.g., 2006), Frankenstein (e.g., 2001), Brantlinger (2013) and others, mainly based on Freire's (1968/1996) fundamental theoretical ideas concerning literacy, oppression and human rights in schooling in South American contexts. Critical mathematics education from this perspective is also ethnomathematical in several aspects. For example, Gutstein (2010) reported on his action research in a classroom in which "reading and writing the world - with mathematics — were very much the agenda" (p. 272). He carefully described cultural aspects of the classroom and thus exercised a particular form of ethnomathematics in his reporting, in addition to leading his students in cultural situated work (Andersson \& Wagner, 2015). This may be different from analysing ethnomathematics in a culture in which the researcher is not actively taking part.

The way that we have described critical mathematics education might be regarded as a kind of mathematics arising in specific cultural contexts. The mathematics is different in the different contexts but of course they have similarities as they represent people responding to similar problems-in this case they are responding to inequities in their societies. Similarly, our analysis of the MES proceedings (Andersson \& Wagner, 2015) considered the demographic and geographic contexts of ethnomathematical work. We did not describe ethnomathematics as abstracted knowledge, but rather we situated it in the cultural context of mathematics education research. This was an ethnomathematical move. But it was also a critical mathematics education move, because the move was motivated by the kinds of concerns that drive critical mathematics education.

We note that in this book, with its strong focus on critical mathematics education, there are two chapters that focus on ethnomathematics and how ethnomathematical teaching and research may be addressed as critical mathematics education. Like Lunney Borden, and Parra and Valero (both this volume), we are motivated to connect the two. Both Lunney Borden and Parra have written about their research in Indigenous settings and have raised political, decolonising questions. We note that these researchers have conducted their research in the Americas - in Colombia and Canada - where the critical mathematics education tradition usually explicitly or implicitly is informed by the theoretical ideas developed by Freire (i.e. 1968/1996).

\section{The Concerns of Culturally Situated Critical Mathematics Education}

Given the connections between ethnomathematics and critical mathematics education, we present a set of concerns focusing on a synthesis of the two. We 
call these the concerns of culturally situated criticalmathematics education. With this adjusted list of concerns (adjusted from the list from Skovsmose and Nielsen, 1996), we would see any ethnomathematics or critical mathematics education work as fitting. The importance of this unified set of concerns is that critical mathematics education work can benefit from attending to the ethnomathematical concerns that are added into the framework, and vice versa. We acknowledge that there are examples of scholarship that already straddle the line between these two traditions. Parra and Valero (this volume) and Lunney Borden (this volume) are examples of this. For another example, we point to the work by Knijnik (2012) who introduced power concerns into her ethnomathematical work:

Introducing power into the ethnomathematical discussions avoided a naïve understanding of the mathematical diversity. Making power explicit in ethnomathematics could allow us to analyse how the politics of knowledge operates in schooling processes and, in particular, in the mathematics curricula. (p. 89)

Our list of concerns, given below as the things we pay attention to in culturally situated critical mathematics education, borrows heavily from Skovsmose and Nielsen's (1996, p. 1257) list, and has been developed in our process of reading and writing about ethnomathematics and critical mathematics education over time.

1. Analysing community features: Mathematics may serve as a tool for identifying and analysing critical features of a community, which may include its global context but must focus on the local context of students.

2. Focusing on acting persons: Educational practice must be understood in terms of acting persons. This means that pure, abstracted knowledge is not sufficient. Instead, the focus is on mathematical practices of people in the community, including students as active citizens.

3. Reflecting on mathematics: Mathematics is not only a tool for critique but also an object of critique. Educational practice must reflect on the role of mathematics in relation to inequities. It asks how the mathematical and mathematics education practices in the community, initiate, reproduce, sustain, or transform inequalities. Whose needs are favoured?

4. Reflecting on education: Culturally situated critical mathematics education is attentive to life in the classroom. It recognises that communication among teachers, students and others in the school milieu can reflect, create and sustain power relations.

We compare our list of concerns with the list from Skovsmose and Nielsen (1996) in Table 2.1. The first concern identified by them-promoting "preparation of students to be an active part of political life" (p. 1257) —encompasses all 


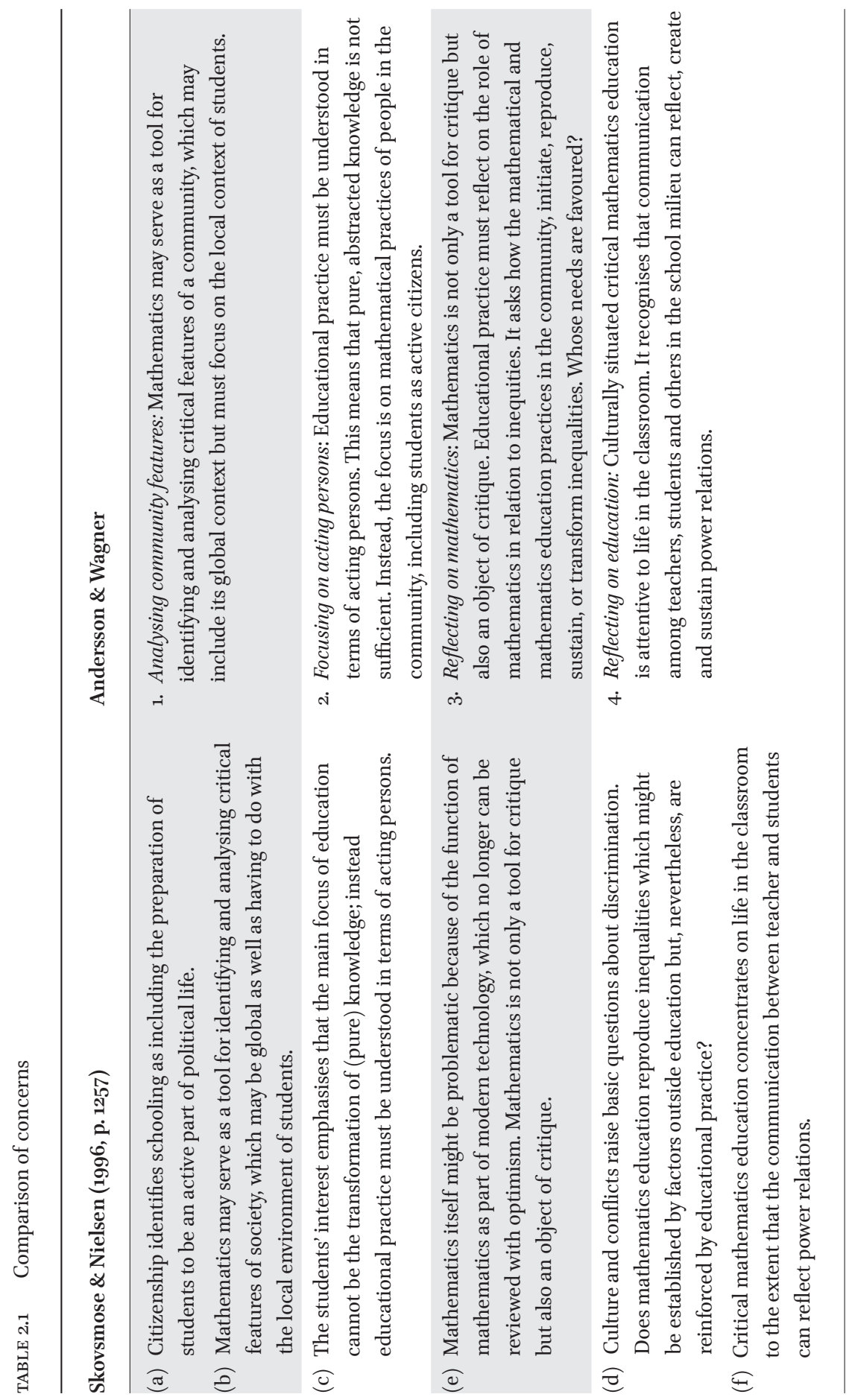


concerns, in our view and is thus not represented separately in our list. The second concern in our list emphasises the active aspect of the concern expressed by Skovsmose and Nielsen, but our articulation differs in that we want to see the students already active politically, not only preparing to be active later. Following this orientation to action, our labels for each concern focus on action.

Our first concern is very similar to the second concern identified by Skovsmose and Nielsen. We have emphasised the need to address local contexts, which was not a requirement in the way they articulated the concern. This local emphasis is something we think ethnomathematics contributes to critically minded mathematics educators. Our second concern is a rewrite of the third concern identified by Skovsmose and Nielsen. We turned it around to start with the positive statement - what mathematics should do, instead of what it should not do. The focus on the actions of people in the community is clearly an ethnomathematical concern. Connecting the students' actions to the actions of community members brings critical mathematics education and ethnomathematics together. Our third concern is a rewrite of the fifth concern identified by Skovsmose and Nielsen. Our fourth concern brings together the fourth and sixth concerns identified by Skovsmose and Nielsen, which are closely related to each other.

We will illustrate our four concerns by using them to analyse two articles, one that would normally be seen as ethnomathematical and one that would normally be seen as an example of critical mathematics education. This analysis aims to show how the concerns bring the strengths of ethnomathematics to critical mathematics education and vice versa.

For the purpose of this chapter, we analysed two published journal articles: one representing ethnomathematical research and teaching by Nutti (2013) with the title "Indigenous Teachers' Experiences of the Implementation of Culture-based Mathematics Activities in Sámi School"; and another representing critical mathematics education research and teaching by Rubel et al. (2016) entitled "Teaching Mathematics for Spatial Justice: An Investigation of the Lottery." Nutti's research presents teachers' reflections on a cultural based mathematics teaching during an ethnomathematical teaching sequence in a Scandinavian Indigenous setting with the intention to recreate a Sámi cultural activity in a mathematical school context. Rubel et al.'s work is situated in a disadvantaged community school in northern America, a school where 
all students are identified as having relatively low socioeconomic status (they qualify for free or reduced lunches) and all are identified as Hispanic ( $75 \%)$ or Black (25\%). The research focuses on students and their mathematical learning during a teaching sequence based on place-based pedagogies. The teachers in their study led students in using digital technologies to map the location of money spent on government-sponsored lotteries in their city and the location of distributed profits from these lotteries. Their work identified which neighbourhoods gained money from the lottery system and which neighbourhoods lost money.

We chose these two articles with the following criteria in mind. First, we wanted articles that described exemplary practices. Second, we wanted articles by scholars who are not the most commonly cited authors in relation to critical mathematics education and ethnomathematics. In other words, these are scholars who are drawing on powerful traditions of mathematics education to impact their practices locally. We also wanted a geographical difference-hence research conducted on different continents.

Methodologically, the two research projects show similarities. Nutti labeled her methodology as action research, conducted in teaching circles with evaluations after each sequence. Rubel et al. identified their work as grounded theory research, conducted in iterations with evaluations in between the iterations. Both used data collected from observations, interviews and field notes. In other words, both these articles represent research and teaching sequences with teachers collaborating with researchers, on an action research/iterative/ emancipatory basis.

There are similarities and differences in the results presented by these researchers. Nutti's research addresses social justice concerns: Indigenous teachers are not using mathematics textbooks in Sámi because they have found that the textbooks did not lead to Sámi culture-based teaching, as the textbooks were translated. During the research period, a lack of suitable teaching materials - culturally relevant textbooks, national curricula, and testsforced the teachers to become creative in order to implement culture-based teaching. Teachers "began to act as potential agents of Indigenous school transformation by starting to work with Sámi culture-based mathematics activities" (Nutti, 2013, p. 69). In addition, her research confirms prior research findings in other contexts1: Indigenous knowledge was seen by textbooks as less important than western school mathematics and thus teachers chose not to implement a culture-based teaching approach, due to "their wish to prepare the pupils in "the best possible way"' (p. 70). Despite these concerns and challenges, the teachers became self-empowered by the work and teaching experiences, became "agents for school-change" (p. 71) and engaged further in the design of a Sámi culture-based mathematics education syllabus. 
Rubel et al. reported higher student engagement and improved mathematical learning during teaching sequences on spatial justice. They stressed that students' interest in the digital and mobile technologies increased their activities in the classrooms compared with their usual mathematics teaching. The article is rich in students' voices (with extensive quotations) on mathematics, mathematical findings and problems, and complex reflections on social justice. However, the different approach to teaching also "introduced an element of challenge to their mathematics class" (Rubel et al., 2016, p. 12), according to the collaborating teachers.

We synthesise our findings from these two articles to say that when teaching becomes contextualised into cultural or familiar out-of-school contexts, and connects to experiences of social injustice, students' engagement in mathematical learning increases. However, teachers need support during implementation phases of new or different ways of acting and teaching in the classroom. This observation confirms prior findings by, for example, Andersson (2015), Lasky (2005), and Clarke (2007).

We now analyse these two articles in relation to the four concerns of culturally situated critical mathematics education. In this analysis, we emphasise how the concerns bring ethnomathematical concerns to critical mathematics education and vice versa.

\subsection{Analysing Community Features}

Both articles detail the local contexts and environments of the students and their families. These environments are also related to the global context, such as, for example, the impact of colonisation and boarding schools in the Indigenous context, or growing up as a Black or Hispanic student in disadvantaged circumstances. The importance of knowing (western) mathematics (also a global context) or following a national syllabus in mathematics is problematised in both cases. Both articles then describe challenges faced by mathematics teachers who want to acknowledge students' cultural and societal backgrounds. For example, Nutti states that "The goal of Indigenous education is that it should be approached on the basis of the Indigenous language and culture; this is also the case with Sámi education" (p. 57).

Nutti described how participant "teachers' work with culture-based mathematics activities took the form of Sámi cultural thematic work with ethnomathematical content, multicultural school mathematics with Sámi cultural elements, and Sámi intercultural mathematics teaching" (p. 63). She emphasised how the widespread failure to implement culturally relevant teaching was a result of teachers having responsibility without resources, and thus connected local challenges to national policies (not quite global, but at least beyond the local): "It is therefore up to each teacher to design and develop a 
culture-based Sámi education by transforming cultural knowledge into teaching, with the result that no cultural implementation usually takes place in mathematics" (p. 58).

Rubel et al. used a place-based education framework and noted that it "is less frequently described with respect to mathematics in the literature and is another approach to context-based learning that centers on phenomena in students' local, physical environments" (p. 1). Place-based education emphasises local issues, which is a departure from Skovsmose and Nielsen's critical mathematics education concerns, but is not unlike some USA-based versions of critical mathematics education. Rubel et al. referred to critical mathematics research developed in the Americas, stating that "Learning more mathematics enables students to access a range of opportunities beyond the gate usually outside of the neighborhood" (p. 2). They quoted Frankenstein and Gutstein, both situated in the USA, to identify how they "view mathematics as an agentive tool that can support students from within their neighborhoods to fight for the neighborhood and demand justice and equity on its behalf" (p. 2). In a similar way, Nutti wrote that the "key to Sámi up-bringing was for children to become iešbirgejeaddji, independent, and to birget, manage" (p. 61). This empowerment both for teachers and their students was situated in their respective local contexts. Nutti concluded that "in order to support the teachers to become agents for school change, they need Indigenous knowledge, mathematics knowledge, and mathematics education knowledge, followed by the possibility to integrate the Indigenous culture into mathematics teaching" (p. 70). Similarly, Rubel et al. described how they supported teachers' interest in using mathematics for empowering their students: "The research questions consider how the spatial focus supported the learning of mathematics and provided opportunities for students to think critically about the lottery using that mathematics" (p. 1).

We note that despite the geographically, culturally and socially contextual differences between the research settings, there are similarities in how the research and ethics were addressed, how well the context is described and how the local school contexts have an impact on the teaching and research. The empowerment apparent in both research projects identifies them as emancipatory research. Both critical mathematics education and ethnomathematical research and teaching have strong potential to use mathematics as a tool for identifying and analysing critical features in both the local and global contexts that impact what happens in mathematics classrooms. These articles show how mathematics may better serve both students and teachers in a particular community. 


\section{2 $\quad$ Focusing on Acting Persons}

Following the first concern about the importance of how mathematics plays out in local and wider contexts, this second concern focuses on actions by people in the different mathematics (education) practices. These people can be students, teachers and researchers as featured in the two articles here, but may include other actors, including most importantly (from an ethnomathematics perspective) members of the community doing mathematics (or not doing it when they could be). As shown in both articles, but more explicitly in Nutti's work, other actors may include textbook authors and curriculum writers and politicians, all of whom impact from a distance action, decision-making and changing practice locally in schools.

Nutti described changes in teacher actions during the study: "the teachers changed from a problem-focused perspective to a possibility-focused culturebased teaching perspective characterised by a self-empowered Indigenous teacher role, as a result of which they started to act as agents for Indigenous school change" (p. 69). To give two examples, Nutti stated that a "central factor in the teachers' work with Sámi culture-based mathematics activities was the ethnomathematics research field" (p. 69) which justified both a more culturebased mathematics education "as well as legitimising school transformation and enabling the teachers to overcome the limitations imposed by textbooks, national curricula, and tests" (p. 69).

Rubel et al. also described how their project engaged students in action to analyse and understand better significant aspects of their community, namely the publicly organised lottery and its effects on the community: "Findings include student interest in and engagement with the theme of the lottery familiar from outside of school with associated social justice implications" (p. 20). They concluded that "youth can traverse urban spaces on foot with mobile technologies to learn in place and mapping technologies can be used in the classroom as a way to study about place" (pp. 2-3).

Neither of the papers explicitly addressed relationships of power between the actors in the classrooms and the research group. We think it is likely that these relationships were addressed in the research - for example, we see that Rubel et al. showed awareness of possibilities for agency in the relationship: "the topic of the lottery as a spatial justice issue was not co-constructed with students [...] but selected by a design team comprised of individuals neither demographically similar to the students nor local to their neighborhoods" (p. 21). We are told that students developed critical stances about the lottery, which addressed power relations outside the classroom. Implicitly, we can read into the research texts concerns for the teachers' work situations, time 
and space issues and empowerment of teachers while moving into new ways of teaching. There is also evidence of care taken for students and their cultural and societal situation.

\subsection{Reflecting on Mathematics and on Education}

Our analysis of the articles shows that it is difficult to separate reflection on mathematics in society from reflection on school practices. However, we think that both are important forms of reflection and thus deserve to be separate concerns. Here we analyse the two articles on these two concerns together because the authors wrote about them in conflated ways-for example, Nutti (2013) wrote about reflection as follows:

The teachers' self-critical examination can be viewed in the light of Laenui's (2000) decolonisation concepts: "rediscovery," "mourning," "dreaming," "commitment," and "action." The teachers' active engagement, and visions of culture-based teaching and its implementation were central. They tried to rediscover or reinvent Sámi culture in a mathematics school context. (p. 69)

This concern moves from specific actions in a context towards general practices in mathematics education. In the Indigenous context, two main concerns regarding discrimination and its impact were addressed. Both related to aspects of colonisation and its impact on the communities, families, language and relationships, historically and currently. Nutti recognised that the "concept of 'decolonisation' was visible in the teachers' narratives" and that the teachers' theme work in their teaching "had a decolonisation perspective, as the teachers wished to provide the pupils with an opportunity to learn Sámi traditional knowledge such as reindeer counting terms, Sámi traditional body measurements, and the way of measuring snow depth" (p. 64). Rubel et al. also moved to generalise in their conclusions: their pedagogical focus (critical mathematics education) "encourages students to 'decolonise' place by recognising and repudiating the unjust forces that intersect it and to "reinhabit" place by engaging its local features in spite of negative, impactful external forces" (p. 3).

Nutti "detected a conflict between Indigenous teachers' wish to give the pupils an education equal to the teaching in the national school and culture-based teaching, [...] there was a conflict between preparing the pupils for education in the national school and providing them with specific Sámi culture-based knowledge" (p. 67). In contrast, Rubel et al's article showed rich examples that the critical mathematics education and place-based teaching approaches enriched the students' (western) mathematical and social justice knowledge. The teachers' 
narratives and experiences reported by Nutti in addition addressed obstacles, including "shortage of time, restrictions due to national syllabuses and tests, disinterested parents, limited resources, and lack of knowledge of Sámi culture-based mathematics teaching" (pp. 67-68). She concluded that if "teaching materials based on Sámi culture [had] been available, the teachers might have been able to work with further implementation work" (p. 68) and she asked for the development of an Indigenous mathematics curriculum. By contrast, Rubel et al. found that through using the available curriculum, teachers could develop tasks that required students to learn the expected mathematics, as well as opening up "the power of maps toward redefining place to people" (p. 5).

This concern demands reflection on how mathematics and mathematics education practices reproduce, initiate and/or sustain inequalities. To implement Indigenous curriculum in a respectful and peaceful decolonising way, conceptions of mathematics itself seem to present significant problems related to the myth of culture-free mathematics. This concern extends to mathematics education research, as we have noted in our previous work that critiques of ethnomathematics seem to be raised mostly by western scholars, while Indigenous researchers use ethnomathematical research to raise social justice concerns in their communities.

The use of mathematics as a tool for critique, which is part of this concern, is well-developed in Rubel et al.'s teaching and research. Part of their article's aim was to show how "mathematics can be used to analyze, critique, and respond to issues of social as well as spatial justice" (p. 1):

A word wall activity revealed an array of associations with places in their neighborhoods ("cornerstore," "gas station," "supermarket," and "vending machines") and with their families ("grandfather," "grandmothers (Doreen)," and "uncle"). Students named specific groups of people; the descriptors mostly aligned with demographics of people in their neighborhoods ("Puerto Ricans" and "poor people"). Despite some positive associations with the lottery ("fun to do," "happy," and "hope"), students expressed a sense that winning the lottery is a matter of low probability ("one-in-a-million") and high-lighted darker connotations ("broke," "sad," "so pissed," "addiction," and "drug"). Some students expressed indignation at what they sensed was an unfair outcome of the lottery ("they take half your money") perhaps affecting specific groups of people differently, such as by race ("black people don't win"). (p. 10)

Neither of the articles addressed the complementary concern-mathematics as an object of critique. However, we find implicit critiques in both of them: 
mathematics is used to maintain colonisation practices through the western textbooks not recognising Sápmi language or specific Sámi ways of counting, and the lotteries are developed to take "half your money." Nutti found that the main motive for teachers' choices "appeared to be the teachers' desire to prepare the pupils in 'the best possible way' for further studies in the municipal compulsory school system" (p. 67). The teachers' concern suggests the question: What if they had a Sámi culture-based mathematics teaching instead, with Sámi cultural thematic work with ethnomathematical content based on Sámi ontology and epistemology, with a decolonisation perspective? A more explicit critique would lead to further questions, including: Who decides, and where is the power of western mathematics located? The subtle authority of the curriculum discourse dismisses ethnomathematics as a teaching and research subject as we have shown above. This dismissal may also be the case with critical mathematics education teaching and research, which is more commonly described as possible (and fruitful) specifically in disempowered, poor and disadvantaged contexts. However, it could be used in all contexts to address, understand and impact, for example, environmental issues (as illustrated by some of the other chapters in this volume). In other words, dominant European and western mathematics teaching might also find more motivated students (Andersson et al., 2015), benefit from cross-subject activities (Andersson, 2011) or empower students to act and critique with mathematics and to critique mathematics itself.

There was opportunity for the students in Rubel et al.'s work to analyse and critique both mathematics and technologies, but this opportunity was not taken up. The case is rather the opposite as mathematical and technological discourses were honoured as tools of critique:

Students were supported to learn mathematics and to build on that mathematics to develop critical opinions, with greater success at narrower levels of spatial scale. New possibilities generated by using mobile technologies toward participatory mapping were demonstrated with respect to teaching mathematics for spatial justice. The design process and its associated technological tools are adaptable to new themes and places. (p. 21)

As with explicit reflection on mathematics, neither of the papers explicitly addressed concerns of power and authority, or the relationships between the actors in the classrooms and research. If awareness of these concerns was addressed during the research phase we do not know, but the adopted emancipatory research methodologies lead us to believe that authority, agency, and positions would have been carefully and ethically taken into account. We have 
addressed the possibility for reflecting on power and authority in the previous section.

We know that students developed critical stances about the lottery. In other words, the students were presented with (mathematical) tasks and expected to develop certain kinds of mathematical and social justice knowledge while solving the problems: "Engaging with the Local Lotto maps provides opportunities for statistical analysis and critical orientations toward the represented statistics" (p. 5). What if the students had been part of the designing, or if possibilities for students' agency had been opened up? What knowledge would they have developed? A similar question could be asked of Nutti's work: How could the students have been part of the decision making around the development of Samí-based content? What would they have learned?

Discussion

We have presented a framework for culturally situated critical mathematics education, where the similarities and intersections between ethnomathematics and critical mathematics education bring the values and significance of each to the other. We have developed this less dense framework, while recognising Skovsmose and Nielsen's (1996) framework and others' critical stance towards ethnomathematics. We argue that the similarities and intersections imply a rethinking of how we can analyse and write up research that is recognised as cultural, contextual and political as we find both approaches emancipatory and decolonising.

To close, we return to questions about who does ethnomathematics and the related question about who does critical mathematics education. We wonder if our synthesised concerns would help mitigate the avoidance of ethnomathematics we have identified. Using the concerns to analyse the articles may present opportunities for a deficit assessment of either critical mathematics education or ethnomathematics. However, the concerns helped us to identify aspects that often are missing in critical mathematics education - things that ethnomathematics usually does - and vice versa. Instead, our use of the concerns to analyse the articles actually helped us appreciate the research even more, because the framework drew our attention to the power of and care taken in the research. In other words, the analysis also highlighted opportunities.

The reasons for avoidance, building on Barthes' (1972/2009) arguments about myths, all relate to the fear of engaging in morally and ethically challenging terrain. Our list of concerns is unlikely to ease this fear. Engagement in and experiences from critical, ethnomathematical or culturally situated critical 
mathematics education is probably the only realistic way to mitigate this fear. Our list of concerns may highlight how close the two approaches to mathematics education are, and how attention to the foci of both approaches can improve the practice of the both. We hope that these guiding analytical concerns will open up critical questions for researchers within both these paradigms and inform spaces to develop and discuss the cultural, contextual and political concerns in our research fields. We also hope that the concerns will guide scholars researching with critical mathematics education and ethnomathematical orientations. The four concerns - analysing community features; focusing on acting persons; reflecting on mathematics and reflecting on education-each focus on different aspects or levels of mathematical education research. This list of concerns, expressed in this way, can support research writing in both ethnomathematics and critical mathematics education contexts, creating opportunities to learn from the sensibilities of the other, and vice-versa.

\section{Note}

1 See for example Balto (2008) and Meaney (2001), but also Skovsmose for a critical discussion of ethnomathematics in relation to western academic mathematics as a gatekeeper.

\section{References}

Andersson, A. (2011). A "curling teacher" in mathematics education: Teacher identities and pedagogy development. Mathematics Education Research Journal, 23(4), 437-454. https://doi.org/10.1007/s13394-011-0025-O

Andersson, A., Valero, P., \& Meaney, T. (2015). "I am [not always] a maths hater": Shifting students' identity narratives in context. Educational Studies in Mathematics, 9o(2), 143-161. https://doi.org/10.1007/s10649-015-9617-Z

Andersson, A., \& Wagner, D. (2015). Questions from ethnomathematics trajectories. In S. Mukhopadhyay \& B. Greer (Eds.), Proceedings of the Eighth International Mathematics Education and Society Conference (pp. 270-283). Portland State University, Ooligan Press. https://www.mescommunity.info/MES8ProceedingsVol2.pdf

Andersson, A., \& Wagner, D. (2018). Re-mythologizing mystery in mathematics:Teaching for open landscapes versus concealment. Education Sciences, 8(2). https://doi.org/ 10.339o/educsci8020041

Balto, A. M. (2008). Sámi oahpaheaddjit sirdet árbevirolaš kultuvrra boahttevaš buolvvaide: Dekoloniserema akšuvdnadutkamuš Ruoła beale Sámis [Sámi teachers transfer traditional culture to next generations: Decolonizing action research in the Swedish part of Sápmi]. Dieđut, 4, 7-125. https://samas.brage.unit.no/samas-xmlui/ bitstream/handle/11250/177109/Diedut-20o8-4-BOKBLOKKA.pdf?sequence=3 
Barthes, R. (2009). Mythologies. Vintage Classics. (Original work published 1957)

Barton, B. (1996). Making sense of ethnomathematics: Ethnomathematics is making sense. Educational Studies in Mathematics, 31(1), 201-233. https://doi.org/10.1007/ BFoo143932

Borba, M. (1997). Ethnomathematics and education. In A. B. Powell \& M. Frankenstein (Eds.), Ethnomathematics: Challenging Eurocentrism in mathematics education (pp. 261-272). SUNY Press.

Brantlinger, A. (2013). Between politics and equations: Teaching critical mathematics in a remedial secondary classroom. American Educational Research Journal, 50(5), 1050-108o. https://doi.org/10.3102/ooo2831213487195

Clarke, D. (2007). Ten key principles from research for the professional development of mathematics teachers. In G. C. Leder \& H. J. Forgasz (Eds.), Stepping stones for the 21st century. Australasian mathematics education research (pp. 27-39). Sense. https://doi.org/10.1163/9789o87901509_oo4

Dowling, P. (1998). The sociology of mathematics education: Mathematical myths/pedagogic texts. Falmer Press. https://doi.org/10.4324/9780203486870

Frankenstein, M. (2001). Reading the world with math: Goals for a critical mathematical literacy curriculum. In Mathematics: Shaping Australia: Proceedings of the eighteenth biennial conference of the Australian Association of Mathematics Teachers Inc. (pp. 53-64). https://www.aamt.edu.au/Library/Conference-proceedings/MathematicsShaping-Australia/(language)/eng-AU

Freire, P. (1996). Pedagogy of the oppressed (2oth ed. rev., M. Bergman Ramos, Trans.). Penguin. (Original work published 1968)

Geertz, C. (1974). Myth, symbol and culture. Norton.

Gerdes, P. (1997). Survey of current work on ethnomathematics. In A. B. Powell \& M. Frankenstein (Eds.), Ethnomathematics: Challenging Eurocentrism in mathematics education (pp. 331-372). SUNY Press.

Gutstein, E. (2006). Reading and writing the world with mathematics: Toward a pedagogy for social justice. Routledge. https://doi.org/10.4324/9780203112946

Gutstein, E. (2010). Our issues, our people: Mathematics as our weapon. In U. Gellert, E. Jablonka, \& C. Morgan (Eds.), Proceedings of the Sixth International Mathematics Education and Society Conference (pp. 270-279). Freie Universität Berlin. https://www.mescommunity.info/mes6b.pdf

Herbel-Eisenmann, B., \& Wagner, D. (2010). Appraising lexical bundles in mathematics classroom discourse: Obligation and choice. Educational Studies in Mathematics, 75(1), 43-63. https://doi.org/10.1007/s10649-010-9240-y

Jurdak, M. (2016). Learning and teaching real world problem solving in school mathematics: A multiple-perspective framework for crossing the boundary. Springer. https://doi.org/10.1007/978-3-319-08204-2

Knijnik, G. (2012). Differentially positioned language games: Ethnomathematics from a philosophical perspective. Educational Studies in Mathematics, 80(1), 87-100. https://doi.org/10.1007/s10649-012-9396-8 
Laenui, P. (2000). Processes of decolonization. In M. Battiste (Ed.), Reclaiming Indigenous voice and vision (pp. 150-16o). UBC Press.

Lasky, S. (2005). A sociocultural approach to understanding teacher identity, agency and professional vulnerability in a context of secondary school reform. Teaching and Teacher Education, 21(8), 899-916. https://doi.org/10.1016/j.tate.2005.06.003

Meaney, T. (2001). An indigenous community doing mathematics curriculum development. Mathematics Education Research Journal, 13(1), 3-14. https://doi.org/10.1007/ BFo3217095

Mellin-Olsen, S. (1987). The politics of mathematics education. Reidel.

Nutti, Y. J. (2013). Indigenous teachers' experiences of the implementation of culturebased mathematics activities in Sámi school. Mathematics Education Research Journal, 25(1), 57-72. https://doi.org/10.1007/s13394-013-0o67-6

Parra, A. (2018). Curupira's walk: Prowling ethnomathematics theory through decoloniality (Doctoral dissertation). Aalborg Universitet. https://doi.org/10.5278/ vbn.phd.eng.0005०

Rowlands, S., \& Carson, R. (2002). Where would formal, academic mathematics stand in a curriculum informed by ethnomathematics? A critical review of ethnomathematics. Educational Studies in Mathematics, 5o(1), 79-102. https://doi.org/ 10.1023/A:1020532926983

Rubel, L. H., Lim, V. Y., Hall-Wieckert, M., \& Sullivan, M. (2016). Teaching mathematics for spatial justice: An investigation of the lottery. Cognition and Instruction, 34(1), 1-26. https://doi.org/10.1080/073700o8.2015.1118691

Skovsmose, O. (1994). Towards a philosophy of critical mathematics education. Kluwer. https://doi.org/10.1007/978-94-017-3556-8

Skovsmose, O. (2001). Landscapes of investigation. Zentralblatt für Didaktik der Mathematik, 33(4), 123-132. https://doi.org/10.1007/BFo2652747

Skovsmose, O. (2010). Critical mathematics education: In terms of concerns. In B. Sriraman, C. Bergsten, S. Goodchild, G. Palsdottir, B. Dahl Søndergaard, \& L. Haapasalo (Eds.), The first sourcebook on Nordic research in mathematics education (pp. 671-682). Information Age.

Skovsmose, O., \& Nielsen, L. (1996). Critical mathematics education. In A. J. Bishop, K. Clements, C. Keitel, J. Kilpatrick, \& C. Laborde (Eds.), International handbook of mathematics education (pp. 1257-1288). Kluwer. https://doi.org/10.1007/978-94-oo91465-o_36

Wagner, D. (2019). Changing storylines in public perceptions of mathematics education. Canadian Journal of Science, Mathematics and Technology Education, 19, 61-72. https://doi.org/10.1007/s42330-018-00039-1

Zolkower, B., \& de Freitas, E. (2010). What's in a text: Engaging mathematics teachers in the study of whole-class conversations. In U. Gellert, E. Jablonka, \& C. Morgan (Eds.), Proceedings of the Sixth International Mathematics Education and Society Conference (pp. 508-517). Freie Universität Berlin.

https://www.mescommunity.info/mes6b.pdf 